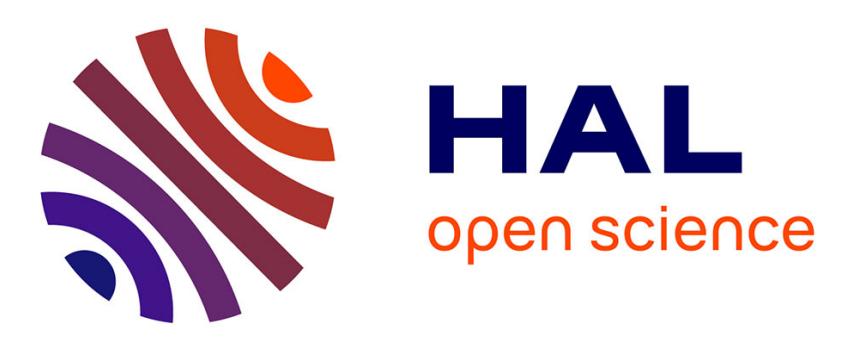

\title{
Finite element simulations of the deformation of fused-cast refractories based on X-ray computed tomography
}

Kamel Madi, Samuel Forest, Michel Boussuge, Sylvain Gailliègue, Emilie Lataste, Jean-Yves Buffiere, Dominique Bernard, Dominique Jeulin

\section{To cite this version:}

Kamel Madi, Samuel Forest, Michel Boussuge, Sylvain Gailliègue, Emilie Lataste, et al.. Finite element simulations of the deformation of fused-cast refractories based on X-ray computed tomography. Computational Materials Science, 2007, 39 (1), pp.224-229. 10.1016/j.commatsci.2006.01.033 . hal00140558

\section{HAL Id: hal-00140558 https://hal.science/hal-00140558}

Submitted on 26 Jun 2007

HAL is a multi-disciplinary open access archive for the deposit and dissemination of scientific research documents, whether they are published or not. The documents may come from teaching and research institutions in France or abroad, or from public or private research centers.
L'archive ouverte pluridisciplinaire $\mathbf{H A L}$, est destinée au dépôt et à la diffusion de documents scientifiques de niveau recherche, publiés ou non, émanant des établissements d'enseignement et de recherche français ou étrangers, des laboratoires publics ou privés. 
Computational Material Sciences, vol. 39, pp. 224-229, 2007.

doi:10.1016/j.commatsci.2006.01.033

\title{
Finite element simulations of the deformation of fused-cast refractories based on X-Ray computed tomography
}

\author{
Kamel Madi ${ }^{1}$, Samuel Forest ${ }^{1}$, Michel Boussuge ${ }^{1}$, Sylvain Gailliègue ${ }^{1}$, Emilie \\ Lataste $^{2}$, Jean-Yves Buffière ${ }^{2}$, Dominique Bernard ${ }^{3}$, Dominique Jeulin ${ }^{1}$ \\ (1) Centre des Matériaux - UMR CNRS 7633, Ecole des Mines de Paris, B.P. 87, 91003 Evry, France \\ (2) GEMPPM, INSA Lyon / Bat. St Exupéry / 20 Av. Albert Einstein F-69621, Villeurbanne cedex, \\ France
}

(3) Institut de Chimie de la Matière Condensée de Bordeaux, ICMCB/ UPR CNRS 9048 / 87, Av. du Dr Albert SCHWEITZER, 33608 PESSAC Cedex, France

\begin{abstract}
This work consists in building a 3D numerical model of the microstructure of a fused-cast refractory (two-phase material). Creep tests at temperatures as high as $1400^{\circ} \mathrm{C}$ reveal a major influence of the morphology of the phases on the material behavior. A possible $3 \mathrm{D}$ connectivity of the zirconia grains, related to the fabrication process, may explain the observed high creep resistance. In order to have a realistic representation of the microstructure, 3D pictures have been obtained using X-Ray microtomography at the European Synchrotron Radiation Facility in Grenoble (ESRF). Volumetric tetrahedral grids are generated from the exploitation of these pictures using available meshing techniques. Finite elements calculations are performed to study the influence of the glassy phase content on the stiffness of the material. Simulations are compared with experiments. In particular the notions of geometrical and mechanical percolation are investigated numerically. High elastic stiffness is predicted, even for large amorphous phase contents. A percolation threshold is observed for the geometry of the hard phase (zirconia phase) but not for the Young's modulus.
\end{abstract}

\section{Introduction}

This work focuses on the study of a zirconia-rich fused-cast refractory used for building glass furnaces. The manufacturing process of fused-cast refractories is similar to that used in metallurgical foundry, that is melting of raw materials at very high temperature, casting into molds and then controlled cooling. The stage of cooling is a critical step in the fabrication process, that strongly influences the quality of the final product. Numerous experimental techniques (tension, compression and bending tests, creep experiments, ultrasonic measurements, etc.) were performed to investigate the material behavior [1, 2]. Our work aims at reaching a better understanding and the simulation of the phenomena occuring during the cooling stage, from the properties of the constituents and from a realistic numerical modeling of the microstructure topology. This work focuses on the original 3D morphology of the investigated material, induced by the fabrication process. The connectivity of the hard phase is shown to play a significant role on the macroscopic mechanical behavior 
of the material. This first contribution concentrates on the elastic behavior of the material. The role played by the constituents on the stiffness of the material is discussed.

(a)
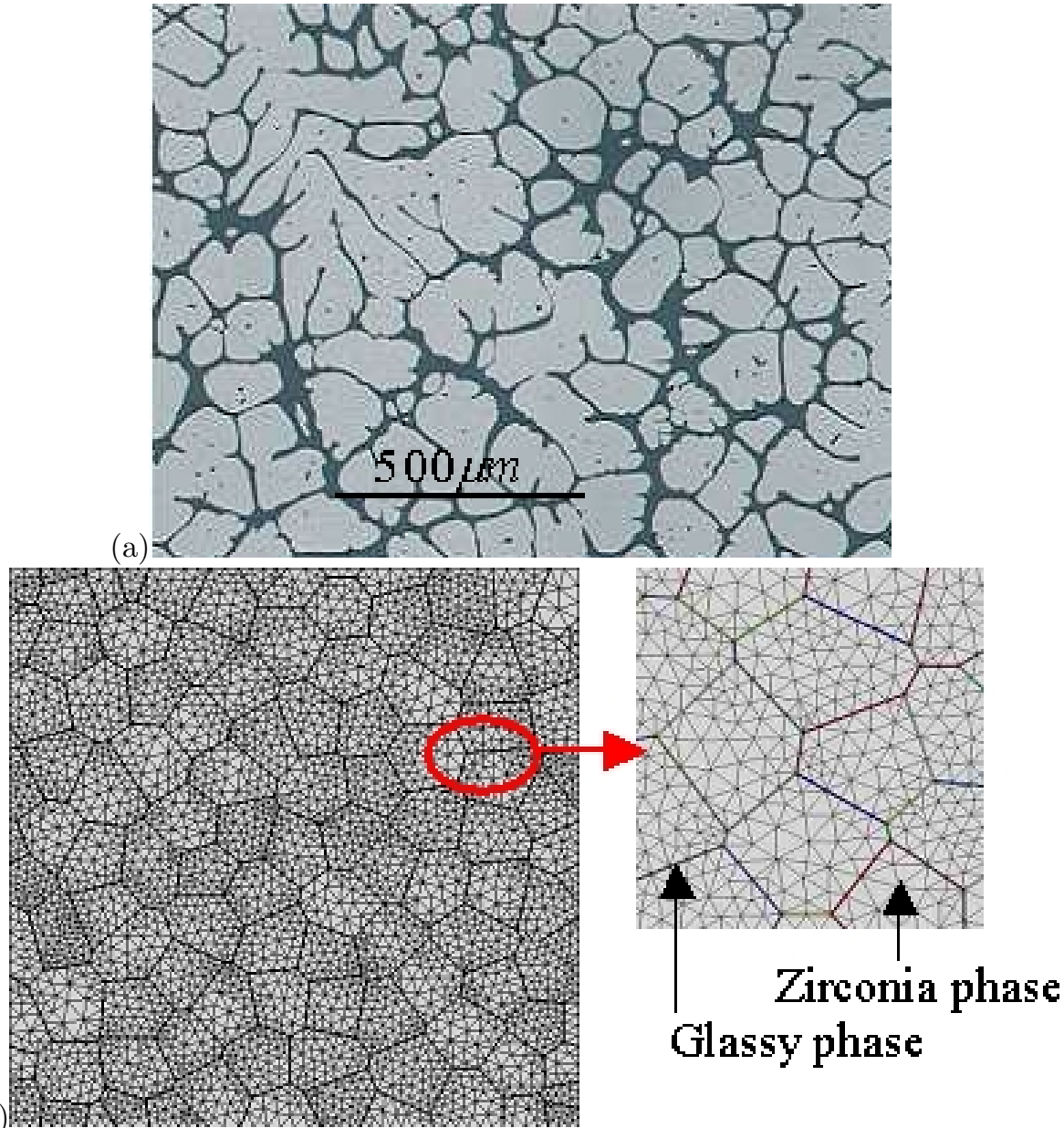

$(\mathrm{b})$

Figure 1: (a) Microstructure of the HZ material (optical micrograph: amorphous phase in dark, crystal zirconia phase in bright), (b) Simulated microstructure with meshed grains boundaries (100 grains).

\section{Microstructure of the material}

\section{$2.12 \mathrm{D}$ representation}

The investigated material, called HZ for High Zirconia content, is a zirconia-rich material (88\%vol. zirconia). 2D optical microscopy (see Fig 1(a)) revealed that zirconia (the hard phase) is surrounded by a darker thin-layer of amorphous phase (12\%vol.) (the weak phase) with a glass transition temperature of about $780^{\circ} \mathrm{C}$. At higher temperatures, the amorphous phase behaves inside the material like a Newtonian fluid with a decreasing viscosity with increasing temperature. Creep tests were performed on this material at temperatures as high as $1400^{\circ} \mathrm{C}$. Surprisingly, they revealed that this material exhibits a high creep resistance up to temperatures $600^{\circ} \mathrm{C}$ higher than the glass transition temperature of the amorphous phase. Moreover, this observation remains true for another fused-cast material of the alumina-zirconia-silica system containing 
$28 \%$ vol. of the same amorphous phase [3]. This kind of behavior is very different from the mechanical response of conventional sintered ceramics at high temperature, that strongly depends on the volume fraction and on the viscosity of the intergranular amorphous phase 4, 5. Preliminary 2D simulations of creep in the HZ material (see Fig 1 (b)) have been performed with a mesh representative of most sintered ceramics (individual grains surrounded by a continuous intergranular phase) [6]. Even when the behavior of zirconia is assumed to be purely elastic, considering the decrease in viscosity of the amorphous phase leads to a strong overestimation of the creep rate when compared to experiments. A Norton creep law with a stress exponent equal to 1 was considered for the glassy phase. This suggests that the $3 \mathrm{D}$ topology of the microstructure could have a great influence on the observed properties and should be investigated.

\subsection{D Morphology}

\subsubsection{X-Ray tomography}

To get a 3D representation of the material, high energy X-Ray tomography at the European Synchrotron Radiation Facility (ESRF, Grenoble, France) has been used. This technique basically consists in recording several radiographs of a sample at different angular positions and in reconstructing a 3D map of the X-Ray attenuation coefficient within the material using adequate algorithm and software [7. This technique can reveal all the microstructural features (inclusions, cracks, pores, constituting phases, etc.) that induce a change in attenuation along the path of the X-Ray beam. From this point of view, there is a high contrast between the high X-Ray attenuation of zirconia compared to that of the amorphous phase. Figure2 2 illustrates a 3D image of the microstructure of the $\mathrm{HZ}$ material obtained with the highest resolution $(1.4 \mu \mathrm{m})$ available on the ID19 beamline (X-Ray energy: $40 \mathrm{keV}$ ) that has been used at ESRF.

\subsubsection{D connectivity of the phases}

In order to study the 3D connectivity of the phases in the material, the concept of geometrical percolation has been used. This notion has been introduced by T. Kanit to study the possible percolation of a phase in a heterogeneous material [8, 9. Using image analysis tools and a mathematical morphology algorithm based on the 3D geodesic reconstruction, two important concepts are defined: (i) the image of the interconnected phase is defined as the set of all points in a given phase that can be connected to two opposite sides of the image following paths entirely contained in the same phase; (ii) the percolation ratio is defined as the ratio between the volume fraction of the interconnected phase to the whole volume fraction in the microstructure of this phase. It is always lower than or equal to 1 . It is equal to 1 if the whole phase is interconnected and equal to zero if there is no percolation of this phase (physically this means that this phase is made of isolated inclusions). Figure 3 represents a 3D picture of the interconnected parts of both hard and weak phases. Figure 3(a) (resp. figure 3(b)) represents the set of all points in the zirconia phase (resp. amorphous phase) that can be linked together to the bottom and top faces of the parallelepiped by paths entirely contained in the zirconia phase (resp. amorphous phase). As a result, all isolated parts of zirconia phase (resp. amorphous phase) were removed. In our case, both phases are interconnected with a percolation ratio equal to $99.8 \%$. Consequently, the high $3 \mathrm{D}$ connectivity of the zirconia phase is a possible explanation of the observed mechanical behavior: high creep resistance up to temperatures $\left({ }^{\circ} \mathrm{C}\right)$ about twice the glass transition temperature of the amorphous phase. 


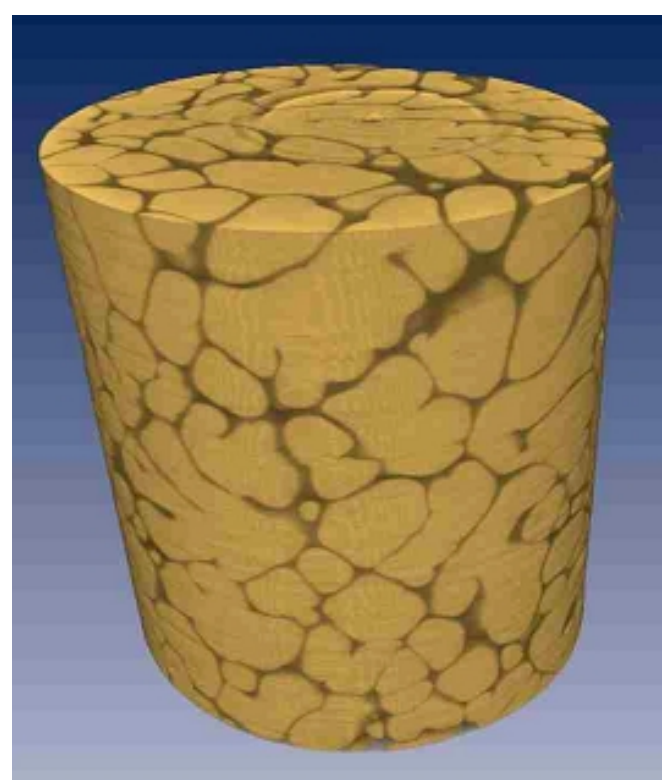

Figure 2: 3D representation of the phases obtained by X-Ray tomography (zirconia in bright, amorphous phase in dark). Diameter of the specimen: $500 \mu \mathrm{m}$, height: $1400 \mu \mathrm{m}$.

\section{Computational method}

\subsection{Finite element meshing}

This paragraph aims at describing available meshing techniques based on tomographic images. Building a finite element mesh from a 3D picture includes three steps: (i) segmentation (in our case binarisation) of the tomographic grey level image to separate the phases, (ii) geometrical definition of the solid boundaries by triangular facets and, finally, (iii) tetrahedral meshing of the solid volume. The challenge is then to mesh a representative refractory volume with an accurate enough geometric description, while keeping a reasonable number of degrees of freedom in the model.

\subsubsection{Segmentation procedure}

The segmentation assigns to each voxel of the image a label determining which phase the voxel belongs to. Images obtained using X-Ray microtomography on HZ material provide a qualitative description of the refractory, because of the good contrast between zirconia and the amorphous phase. Nevertheless, it is recurrent in high-resolution microtomography to obtain ring artefacts. Ring artefacts are represented by marked circular patterns that affect the sections of the reconstructed volume. These artefacts are usually attributed to a non-linear behavior of some pixels of the detector during acquisition and their systematic correction is still a problem. Our images, also altered by these artefacts, must be cleaned before the segmentation step. The filter we used to eliminate partial rings without pertubating the rest of the image was developed by D. Bernard at Institut de Chimie de la Matière Condensée de Bordeaux (France) [10, 11. In our case, the application of this correction procedure has been very effective. Then, the method used to segment our images consists in choosing a threshold, using an histogram of grey levels as a guide. Figure 4 illustrates such an histogram in the scanned volume (see Fig 5 (a)). Two well separated peaks represent the distribution 
(a)

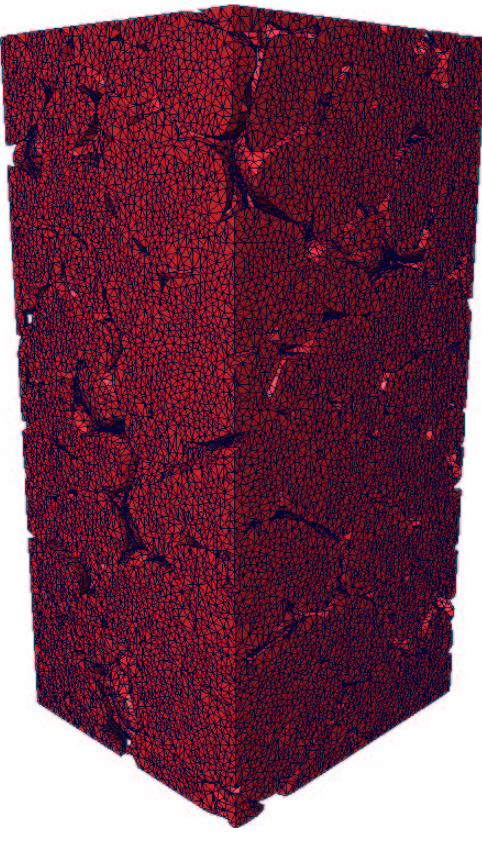

(b)

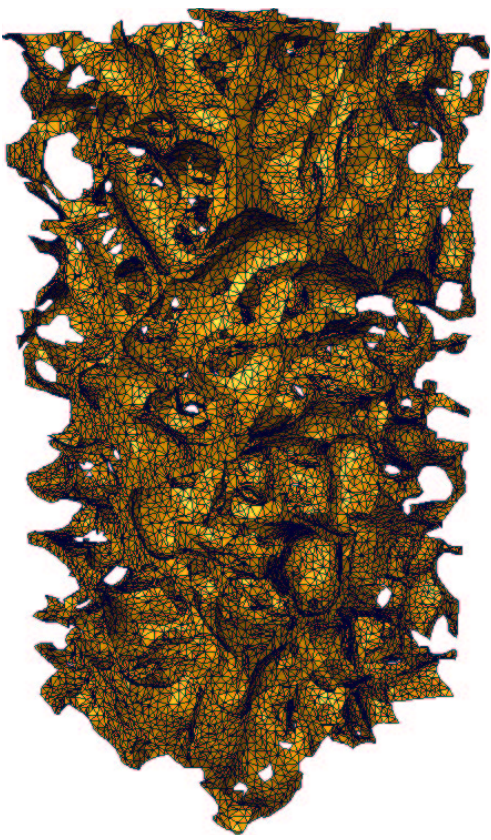

Figure 3: (a) 3D representation of the interconnected parts of the zirconia phase, (b) 3D representation of the interconnected parts of the amorphous phase, $(350 \mu \mathrm{m} \times 350 \mu \mathrm{m} \times 700 \mu \mathrm{m})$.

of the grey levels of each phase respectively. The choice of the threshold is then imposed naturally (a small variation of the volume fraction of the phases is observed when slightly changing the chosen threshold). Then, the program sets to white all voxels that are located beyond the threshold (zirconia phase), and all other voxels of the image to black (amorphous phase). This image processing transformation is illustrated in figure 5 (b).

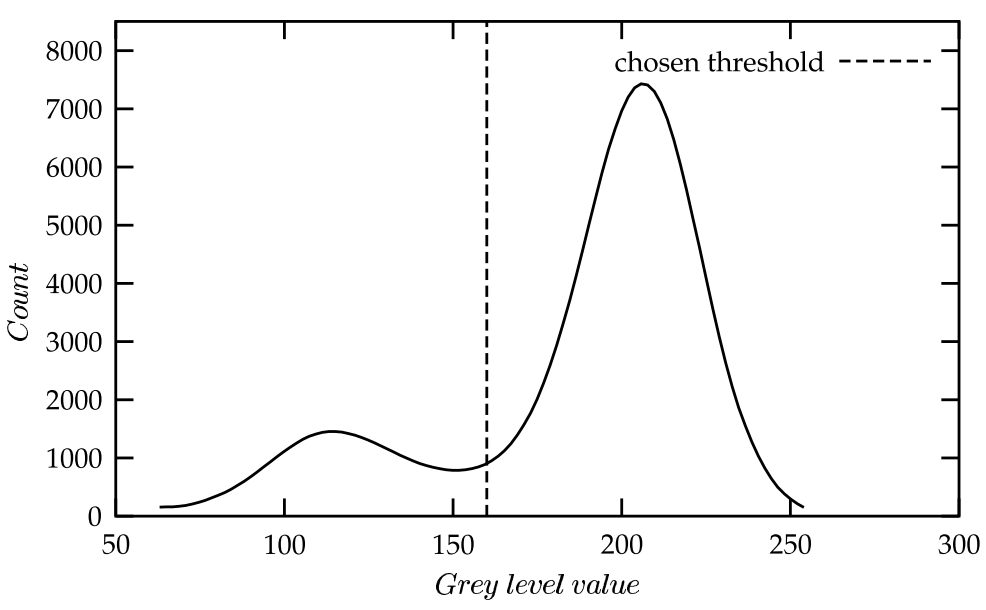

Figure 4: Histogram of the grey levels in the scanned volume. 


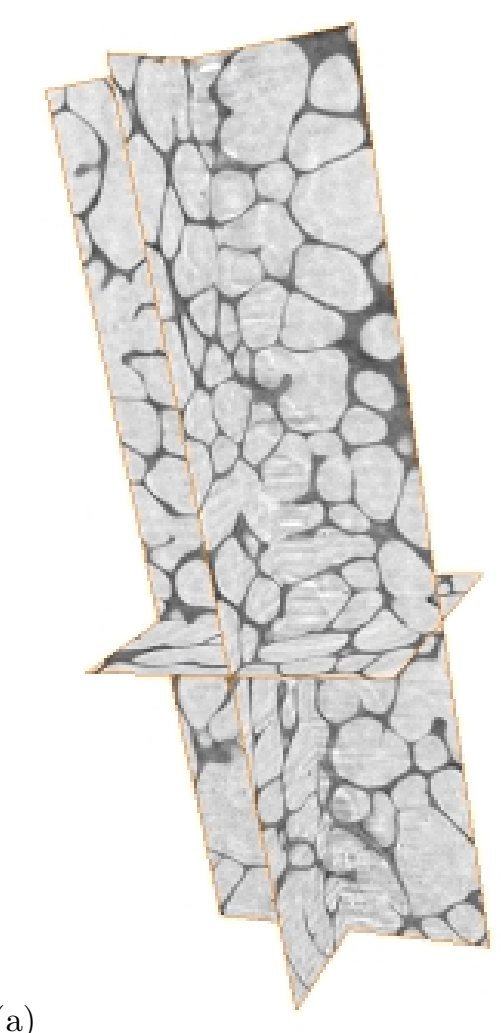

(a)

(b)

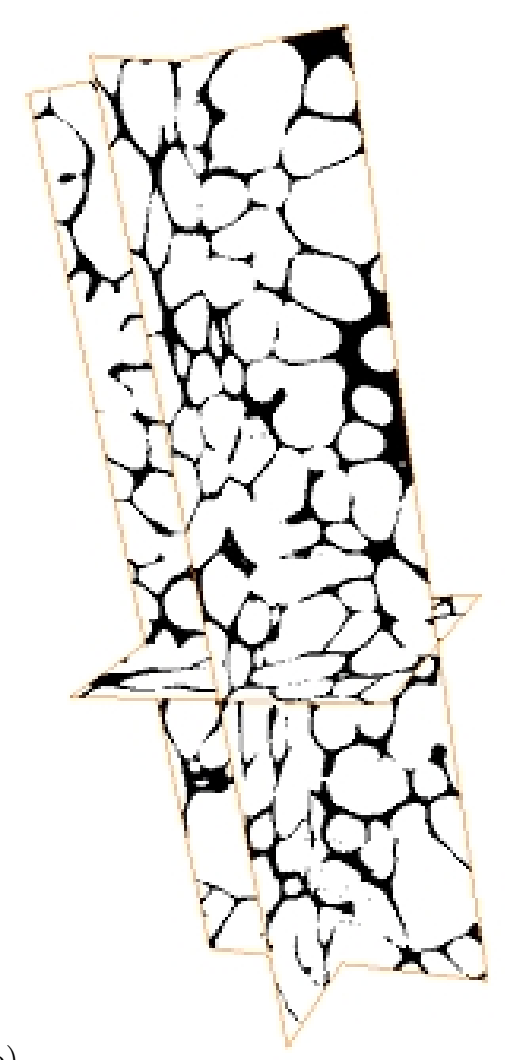

Figure 5: Image processing: (a) scanned volume, (b) binarized volume $(350 \mu \mathrm{m} \times 350 \mu \mathrm{m} \times 700 \mu \mathrm{m})$. Only 3 perpendicular sections are represented for the sake of clarity.

\subsubsection{Mesh generation}

Building FE models from 3D voxels requires that the grids correctly respects the geometry of the phases inside the material. The boundary between the two phases, called the isosurface, has to be well captured before the creation of volumetric grids. Conventional techniques are used to build FE models from 3D voxels. The simplest method uses the natural discretisation of the image by voxels. Then, each voxel belonging to the solid region constitutes an 8-node cubic element of the mesh. This technique, known as the voxelelement technique, is easily implemented [12, 13. However, applying this method to large volumes generates grids with an excessive number of nodes, that would require too much time for calculation. Moreover, this method is unable to capture surface boundaries satisfactorily (it generates jagged boundaries) which can lead to inaccurate finite element analysis results. Another approach consists in generating surface models and is known as triangulation. Triangulated surfaces represent the boundaries between the different phases. In this work, this method was used. The creation of surface models with correct topology and optimized triangular shape from the segmented tomographic data is carried out automatically with the help of the marching cubes algorithm [14, 15], using the Amira software [16]. In the last step, an unstructured tetrahedral mesh is built from the basis of the surface triangulation. Here, meshing has been performed using the advancing front method implemented in the Amira software [17. Figure 3illustrates such 3D grids of the constituents of the HZ microstructure, based on ten-node quadratic tetrahedra, obtained from the stack of segmented images 


\begin{tabular}{|c|c|c|c|}
\hline Phase & Volume Fraction (\%) & $\mathrm{E}(\mathrm{GPa})$ & $\nu$ \\
\hline Zirconia (hard) & 87.2 & 230 & 0.25 \\
Amorphous phase (soft) & 12.8 & 73 & 0.25 \\
\hline
\end{tabular}

Table 1: Volume fraction and Young's modulus at $600^{\circ} \mathrm{C}$ for both phases.

illustrated in figure $5(\mathrm{~b})$.

\subsection{Properties of the constituents}

We made the assumption that the behavior of zirconia remains linear elastic up to $1500^{\circ} \mathrm{C}$. At $600^{\circ} \mathrm{C}$, zirconia is monoclinic. The elastic modulus of monoclinic zirconia versus temperature were calculated from the data obtained on single crystals by Chan and al [18. Assuming the isotropy of the zirconia in the HZ material, the Hill approximation was used to calculate an average value of the stiffness matrix up to the transformation temperature of zirconia. The amorphous phase was considered as having an elastic behavior up to $600^{\circ} \mathrm{C}$. The elastic modulus of the amorphous phase versus temperature was measured by E. Yeugo-Fogaing using an ultrasonic technique [1. Table 1 summarizes the characteristics used for our calculations. It can be noted that the contrast between the Young's modulus of the phases is close to 3 .

\section{Application to the elastic behavior}

In this section, the Young's modulus of the $\mathrm{HZ}$ material at $600^{\circ} \mathrm{C}$ is computed and compared with experiment. The influence of the soft phase content (amorphous phase) on the stiffness of the aggregate is also investigated and linked to the 3D morphology of the constituents.

\subsection{Young's modulus at $600^{\circ} \mathrm{C}$}

\subsubsection{Representative Volume Element}

For determining the size of the RVE, the mechanical properties were studied for different volume sizes. Different parallelepipedic volumes having the same cross section $(350 \mu \mathrm{m} \times 350 \mu \mathrm{m})$ with increasing thickness were extracted from the 3D picture and meshed with the same mesh density estimated to 142 voxels per element. The macroscopic Young's modulus obtained after simulated tensile tests according to the $(\mathrm{Oz})$ direction was investigated. The $(\mathrm{Oz})$ direction is given by the thickness of the volume. Tensile tests at $600^{\circ} \mathrm{C}$ are performed by applying mixed boundary conditions: a displacement is imposed on both faces perpendicular to the $(\mathrm{Oz})$ direction and all the other faces are free of forces. The evolution of the obtained apparent Young's modulus as a function of the volume size is given in table 2 The calculated apparent Young's modulus was normalised by the one calculated for the largest volume (thickness of $700 \mu \mathrm{m}$ ). These ratios are also reported in table 2. The relative error decreases when the size of the domain increases. Except for the smaller aggregates, the relative error is less than $1 \%$. The volume with dimensions $350 \mu \mathrm{m} \times 350 \mu \mathrm{m}$ $\times 700 \mu \mathrm{m}$ has been chosen for our computations at $600^{\circ} \mathrm{C}$. 


\begin{tabular}{|c|c|c|c|c|c|c|}
\hline Thickness of the volume sizes $(\mu \mathrm{m})$ & 3.5 & 35 & 105 & 210 & 490 & 700 \\
\hline $\mathrm{E}(\mathrm{GPa})$ & 203.5 & 202 & 196.3 & 197.2 & 198.5 & 198 \\
\hline Relative difference (\%) & +2.7 & +2 & -0.85 & -0.4 & +0.25 & \\
\hline
\end{tabular}

Table 2: Young's modulus of the $\mathrm{HZ}$ material as a function of the volume size at $600^{\circ} \mathrm{C}$.

\begin{tabular}{|c|c|c|c|c|}
\hline Method & Voigt Bound & Numerical model & Reuss bound & Experiment \\
\hline $\mathrm{E}(\mathrm{GPa})$ & 209 & 198 & 179 & 160 \\
\hline
\end{tabular}

Table 3: Experimental and computed Young's modulus of the aggregate at $600^{\circ} \mathrm{C}$.

\subsubsection{Results}

The values of the experimental and computed Young's modulus at $600^{\circ} \mathrm{C}$ are given in table 3 and compared with the available analytical Voigt and Reuss models. The numerical result is closer to the Voigt bound than to the Reuss bound. It turns out that the mechanical behavior of the aggregate is closer to the one of zirconia than to the glassy phase. This result is due to the fact that the zirconia phase is interconnected inside the volume for the given volume fractions. The elastic modulus of the HZ material versus temperature was measured using two experimental techniques: an ultrasonic technique (E. Yeugo Fogaing) and an impulse excitation technique (E. Lataste). Both experimental values are practically the same (160 GPa). The relative error between the experimental and numerical results is around $20 \%$, which seems to be correct when considering only one volume. It can be noted that the experimental value is slightly smaller than the Reuss bound. This may be attributed to damage that can occur during cooling [1].

\subsection{Effect of the amount of amorphous phase}

In order to study the effect of the amorphous phase content on the Young's modulus of the previous aggregate, successive 3D erosions of the zirconia phase, using image analysis tools, were performed from this initial aggregate. The eroded zirconia phase was replaced by amorphous phase, thus increasing the amorphous phase content. Tensile tests according to the $(\mathrm{Oz})$ direction were then numerically performed on these aggregates. All the aggregates were meshed with the same mesh density (142 voxels per element). The calculated Young's modulus for each aggregate was normalized by the Young's modulus of the individual zirconia phase (230 GPa). The evolution of this ratio as a function of the volume fraction of the amorphous phase is given in figure 6. The 3D connectivity of the zirconia phase, according to the three directions of space, was also investigated as a function of the amorphous phase content. The evolution of the zirconia percolation ratio is illustrated in figure 6. From $70 \%$ of glassy phase content, the percolation ratio decreases to 0 , abruptly according to the $(\mathrm{Oz})$ direction and more progressively according to the other directions. A percolation threshold is observed at about $85 \%$ of amorphous phase. The Young's modulus decreases continuously as a function of the amorphous phase content. Surprisingly, no abrupt drop of the Young's modulus is observed when increasing the amorphous phase content, which reveals a high stiffness of the material. This result can be explained by the progressive stiffness decrease for increasing volume fraction of amourphous phase, due to bending of slender arms of hard phase inside the microstructure. The weak 
chosen contrast (close to 3) between the Young's modulus of the phases is also a possible explanation for the absence of actual mechanical percolation threshold. However, computations with the same microstructures but highe contrasts in the elastic properties between phases, show the same progressive decrease instead of an abrupt stiffness drop.

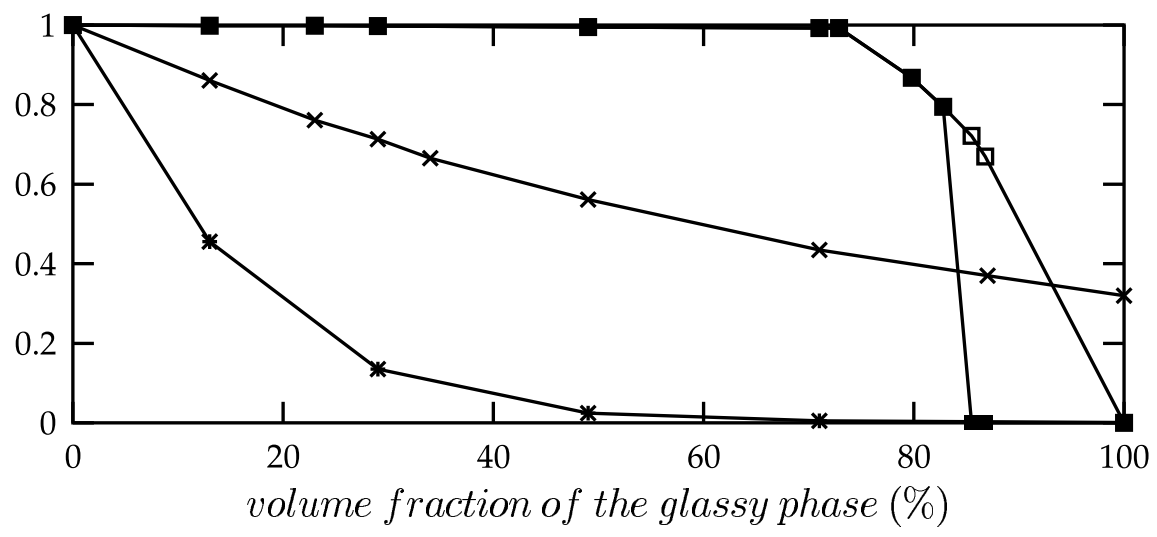

normalized Young's modulus of the aggregate : contrast $=3 \longrightarrow \longleftarrow$ normalized Young's modulus of the aggregate : contrast $=1000 \longrightarrow$ percolation ratio of zirconia/(Ox),(Oy) - $\longrightarrow$ percolation ratio of zirconia $/(\mathrm{Oz}) \longrightarrow$

Figure 6: (a) Evolution of the normalized Young's modulus of the aggregate and the zirconia percolation ratio as a function of the amorphous phase content.

\section{Conclusion}

This paper deals with a zirconia-rich fused-cast refractory used for building glass furnaces. The study of the 3D connectivity of the hard phase (zirconia phase), from 3D pictures obtained using X-Ray tomography, reveals that this phase is practically totally interconnected. The consequences of the high 3D connectivity of the zirconia phase on the macroscopic mechanical behavior of the material are:

- a high creep resistance up to temperatures $\left({ }^{\circ} \mathrm{C}\right)$ about twice the glass transition temperature of the amorphous phase $\left(780^{\circ} \mathrm{C}\right)$;

- high predicted elastic stiffness, even for large glassy phase contents;

- a percolation threshold for the geometry of the phase but not for Young's modulus;

\section{Acknowledgements}

The authors are grateful to ESRF staff (ID19 beamline: E. Boller, E. Pereiro-Lopez, P. Cloetens), E. Yeugo Fogaing (ENSCI, Limoges), F. N'Guyen (ENSMP, Paris), A. Musienko (ENSMP, Paris) and A-F GourguesLorenzon (ENSMP, Paris) for their technical support. This work is supported by the French Ministry of Industry (M. Mussino under grant RNMP "PROMETHEREF") and Saint-Gobain CREE (C. Bert, I. Cabodi, M. Gaubil, Y. Boussant-Roux). 


\section{References}

[1] L. Massard, K. Madi, M. Boussuge, S. Forest, E. Yeugo Fogaing, M. Huger, C. Gault, High temperature mechanical behavior of fused-cast refractories, Advances in refractories for the metallurgical industries IV, fourth international symposium, Hamilton, 2004, ed. M. Rigaud, C. Allaire (2004) 631-644

[2] M. Boussuge, PROMETHEREF : a French research program for the study of thermomechanical properties of industrial refractories, Key engineering materials 264-268 (2004) 1755-1758

[3] L. Massard, Etude du fluage de réfractaires électrofondus du systeme Alumine-Zircone-Silice, Thèse, Centre des Matériaux P. M. Fourt, ENSMP Paris (2005)

[4] K. Hiraga, H.Y. Yasuda, Y. Sakka, The tensile creep behavior of superplastic tetragonal zirconia doped with small amounts of $\mathrm{S}_{i} \mathrm{O}_{2}$, Mat. Sci. and Engng. A234-236 (1997) 1026-1029

[5] F. Wakai, N. Kondo, Y. Shinoda, Ceramics superplasticity, Current Opinion in Solide State and Materials Science 4 (1999) 461-465

[6] A. Musienko, N. G. Cailletaud, O. Diard, Damage, opening and sliding of grain boundaries, IUTAM Conference, Multiscale Modeling and Characterization of Elastic-Inelastic Behavior of Engineering Materials, Marrakech (Maroc) 20-25 Oct. (2002)

[7] E. Maire, J.Y. Buffière, L. Salvo, J.J. Blandin, W. Ludwig, J.M. Letang, On the application of X-Ray microtomography in the field of materials science, Advanced Engineering Materials 3 (2001) 539-546

[8] T. Kanit, S. Forest, I. Galliet, V. Mounoury, D. Jeulin, Determination of the size of the representative volume element for random composites: statistical and numerical approach, Int. J. Solids Struct. 40 (2003) 3647-3679

[9] T. Kanit, F. N'Guyen, S. Forest, I. Galliet, V. Mounoury, D. Jeulin, Apparent and effective physical properties of heterogeneous materials: representativity of samples of two materials from food industry, Comp. Methods Appl. Mech. Eng., in press (2005)

[10] D. Bernard, 3D Quantification of Pore Scale Geometrical Changes Using Synchrotron Computed Microtomography, Oil and Gas Science and Technology-Rev. IFP 60 (2005) 747-762

[11] D. Bernard, A. Chirazi, A Numerical Treatment of Ring Artefacts for the Microtomographic Image Recontsruction and Porous Media Characterization, to be published

[12] E. Maire, F. Wattebled, J.Y. Buffière, G. Peix, Deformation of a metallic foam studied by X-Ray computed tomography and finite element calculations, Euromat 99, ed. T.W. Clyne, F. Simancik, Wiley 5 (1999) 68-73

[13] E.J. Garboczi, A.R. Day , An algorithm for computing the effective linear elastic properties of heterogeneous materials: three-dimensional results for composites with equal phase Poisson ratios, J. Mech. Phys. Solids 43 (1995) 1349-1362

[14] W.E. Lorensen, H.E. Cline, Marching cubes: high resolution 3-D surface reconstruction algorithm, Comput. Graphics 21 (1987) 163-169

[15] S. Youssef, E. Maire, R. Gaertner, Finite-element modelling of the actual structure of cellular materials determined by X-Ray tomography, Acta Mater. 53 (2005) 719-730

[16] Amira, http://wwww.amiravis.com 
[17] P.J. Frey, H. Borouchaki, P.L. George, 3D Delaunay mesh generation coupled wih an advancing-front approach, Comput. Meth. Appl. Mech. Engng. 157 (1998) 115-131

[18] S.K. Chan, Y. Fang, M. Grimsditch, Z. Li, M. Nevitt, W.M. Robertson, E.S. Zouboulis, Temperature dependence of the elastic moduli of monoclinic zirconia, J. Am. Ceram. Soc. 74(7) (1991) 1742-1744 